\title{
Ectopic Pregnancy Combined with Intra-Uterine Pregnancy with a Full-Term Live Baby: A Case Report and Review of Literature
}

\author{
Mamadou Almamy Keita1, Daouda Camara² , Abdoulaye Kanté ${ }^{3 *}$, Assitan Koné1, \\ Abdoulaye Diarra1, Bréhima Coulibaly33, Zoseph Koné4, Seydou Fané5, \\ Cheick Fantamady Camara ${ }^{1}$, Assitan Traoré2 ${ }^{2}$, Bakary Danfaga ${ }^{1}$, Moussa Sogoba ${ }^{1}$, \\ Ismaila Simaga ${ }^{1}$, Bakary Keita ${ }^{6}$, Moussa Konaré $^{6}$, Jules Sangala ${ }^{1}$, Drissa Traoré ${ }^{3}$, \\ Nouhoum Ongoiba ${ }^{3}$
}

\author{
${ }^{1}$ General Surgery Service of the Kati-Mali Reference Health Centre, Kati, Mali \\ ${ }^{2}$ Gynecology and Obstetrics Service of the Kati-Mali Reference Health Centre, Kati, Mali \\ ${ }^{3}$ Service of Surgery "B" of CHU Point G, Bamako, Mali \\ ${ }^{4}$ Service of Anesthesia and Resuscitation of Reference Health Centre, Kati, Mali \\ ${ }^{5}$ Service of Gynecology and Obstetrics of CHU-Gabriel Touré, Faculty of Medicine and Odontostomatology, Bamako, Mali \\ ${ }^{6}$ Service of Anesthesia and Resuscitation of CHU-Gabriel Touré, Bamako, Mali \\ Email: *kanteim@yahoo.fr
}

How to cite this paper: Keita, M.A., Camara, D., Kanté, A., Koné, A., Diarra, A., Coulibaly, B., Koné, Z., Fané, S., Camara, C.F., Traoré, A., Danfaga, B., Sogoba, M., Simaga, I., Keita, B., Konaré, M., Sangala, J., Traoré, D. and Ongoiba, N. (2019) Ectopic Pregnancy Combined with Intra-Uterine Pregnancy with a Full-Term Live Baby: A Case Report and Review of Literature. Case Reports in Clinical Medicine, 8, 29-34. https://doi.org/10.4236/crcm.2019.81004

Received: October 22, 2018

Accepted: January 25, 2019

Published: January 28, 2019

Copyright () 2019 by author(s) and Scientific Research Publishing Inc. This work is licensed under the Creative Commons Attribution International License (CC BY 4.0).

http://creativecommons.org/licenses/by/4.0/

\begin{abstract}
Heterotopic pregnancy is no more a medical breakthrough. It combines intrauterine pregnancy and extra-uterine pregnancy regardless of location. We report a case of intra-uterine pregnancy associated with a ruptured abdominal ectopic pregnancy located on the pelvic colon in a 29 -year-old patient, third gestation, primigravida, having a live baby and a prior history of two abortions. She has blood group $\mathrm{O}$ negative of Rhesus. It has been diagnosed at the stage of the rupture of ectopic pregnancy. An emergency laparotomy performed under blood transfusion has revealed heavy hemoperitoneum $(1100 \mathrm{ml})$, a ruptured abdominal extra-uterine localized on the pelvic under blood transfusion and a bulging uterus. We have proceeded with the aspiration of hemoperitoneum, the ablation of the extra-uterine pregnancy and the hemostasis of the section part. The post-operative follow-up has been easy. The intra-uterine pregnancy has developed normally and has given birth to a full-term live, and healthy baby.
\end{abstract}

\section{Keywords}

Heterotopic Pregnancy, Diagnosis, Maternal and Fetus Prognostic

\section{Introduction}

The coexistence of an intra-uterine pregnancy (IUP) and extra-uterine preg- 
nancy (EUP) in the same patient is a combined pregnancy (CP) also known as heterotopic or ditopian pregnancy [1]. In the past, heterotopic pregnancy was rare but now it is getting more and more observed in hospital practices since the promotion of medically Assisted Reproductive Techniques (ART) on one hand and on the other hand the increase of pelvic infections [2] [3] [4]. Its frequency is differently appreciated by authors. It varies from $1 / 30,000$ spontaneous pregnancies to $1 / 100$ stimulated pregnancies. It was first described by DUVERNET in 1708 during an autopsy [4]. It is a growing health concern due to its emergency feature and aftereffect. Every heterotopic pregnancy presents live threatening conditions of three individuals (the mother and the two embryos/fetus); hence there is urgent need for adequate measures. In maternal health centers, it presents diagnostic and therapeutic difficulties despite the widespread of ultrasound scan and the promotion of emergency services. Its prognostic is highly related to the diagnostic precocity and the efficiency of the treatment. We report the first case of diagnosed heterotopic pregnancy at the stage of rupture of ectopic pregnancy in gynecology and obstetrics department of the Referral health center of Kati.

\section{Observation}

Madam D.K, 29-year-old, third gestation, primigravida, having a live baby and a prior history of two abortions has been referred to the emergency service of the maternity hospital of the Referral health center of Kati in February 18 ${ }^{\text {th }}, 2017$ for paleness and faintness attacks. It was a patient who had been admitted in a private clinic of the city of Kati for severe pelvic pain that has been increasing over 48 hours with delay of menses of more than a month. A urinary pregnancy examination (Beta HCG test) she had undergone was positive and an ultrasound scan performed in emergency had revealed an ongoing singleton intra-uterine pregnancy estimated to six weeks and five days $(6 \mathrm{~W}+5 \mathrm{D})$.

A blood test was run at the same clinic and she was group $\mathrm{O}$ negative Rhesus and the hemoglobin level was $11 \mathrm{~g} / \mathrm{dl}$.

The diagnosis of the doctor of the clinic was the threatening condition of spontaneous abortion, particularly when referring to the prior history of two spontaneous abortions.

Mrs DK has received the following treatment: analgesic and antispasmodic rest resulting in the development of symptoms in first 48 hours, then sudden alteration of her state with the occurring of paleness and faintness attacks. So, she was transported to the Referral health center of Kati.

On admission, her overall vitals were altered with a Glasgow score of 3 over 15, a conjunctival pallor and constant hemodynamic in stability $(B P=90 / 60 \mathrm{mmhg}$, $\mathrm{P} / \mathrm{R}=105 / \mathrm{min}$, heart rate to 27 beats $/ \mathrm{min}$ ). On per abdomen examination, we noted the presence of irritation indications and peritoneal fluid (the cry of the umbilicus and the fluid wave were present). The vaginal or rectal touch has revealed a big uterus with a closed, long, soft and posterior neck, without bleeding 
and increased pain on the left lower quadrant (the presence of the cry of Douglas).

We have immediately performed a median abdominal ultrasound that has shown an intra-uterine pregnancy associated with large amount of hemoperitoneum.

The laboratorypre-operative examination has found out a blood group $\mathrm{O}$ negative and hemoglobin rate at $5.8 \mathrm{~g} / \mathrm{dl}$.

We have immediately done a median laparotomy (Figure 1) performed on blood transfusion. The endoscopic surgery has presented:

- Heavier hemoperitoneum of $1100 \mathrm{ml}$;

- A ruptured abdominal extra-uterine located on pelvic colon and a bulging uterus.

We have proceeded with:

- Aspiration of hemoperitoneum;

- Ablation of EUP;

- Hemostasis of the section slice;

- Abdominal wall closure plan by plan.

In the post-operative phase, the therapeutic protocols given to the patient were:

- Continuous perfusion of 6 ampoules of phloroglucinol trimethylphloroglucinol in Ringer-Lactate solution for injection during 48 hours;

- Intra-muscular injection of Delay-Progesterone;

- Administration of Anti-D blood grouping serum;

- Administration of antibiotics for 7 days.

The patient has received in overall four units of total blood group Rhesus.

The post-operative recoveries were simple. The patient was discharged from the hospital at $\mathrm{D} 10$ of post-operation.

The histology examination confirms the colic seat of EUP with the discovery of fetus structures and colic appendixes in the operation bloc (Figure 2).

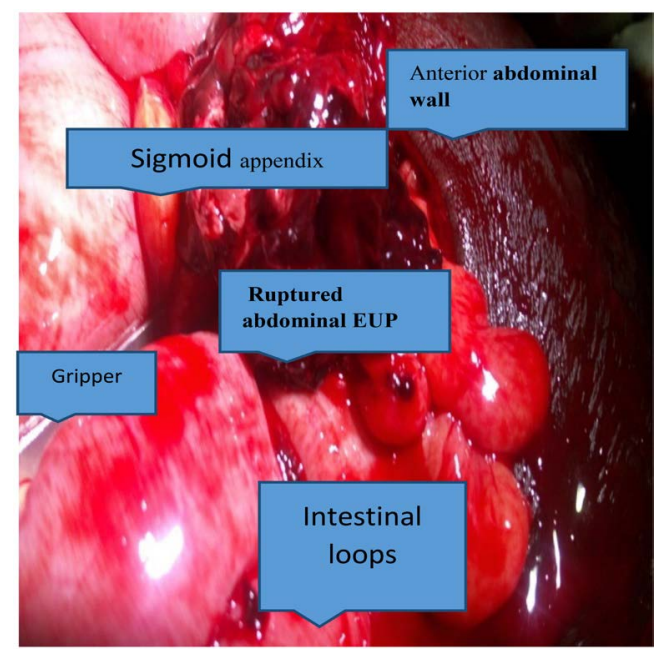

Figure 1. Prior operative image. 


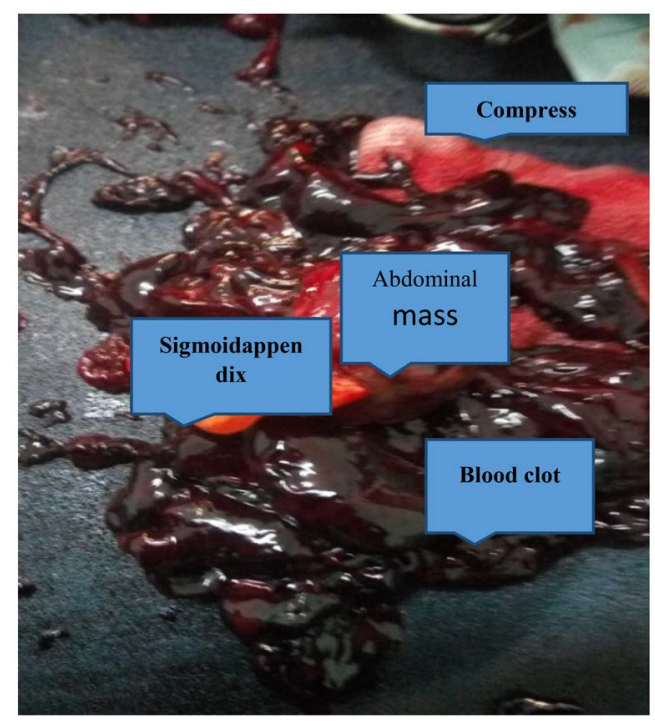

Figure 2. Post-operative image.

The intra-uterine pregnancy has been monitored by the obstetrician gynecologist of the Referral health center of Kati. It has progressed normally and the lady has vaginally given birth to a healthy baby at $39 \mathrm{~W} 2$ days. The baby was blood group $\mathrm{O}$ positive Rhesus, the Anti-D blood grouping serum was administered to the mother in the 24 hours of delivery. The postpartum recoveries were simple.

\section{Discussion}

The heterotopic or combined pregnancy is a pathological association of EUP and IUP in the same patient. It is bi-ovular twin pregnancy in which the nidation of the embryo has occurred in two different areas, one of the two being in uterine cavity [1]. This particular form of twinning is rarely observed on spontaneous pregnancy. Therefore, in a year of activity, we reported one case of spontaneous heterotopic pregnancy out of 2247 deliveries in 2017 and 26 cases of EUP. The frequency noticed in our service is in accordance with that reported in a review of literature where authors [5] [6] indicate the rarity of the pathology. However, nowadays this frequency is increasing pertaining to the rise in medically Assisted Reproductive Technology and the growing of pelvic inflammatory disease (PID) that are the consequences of treated and non-treated Sexually Transmitted Infections (STIs) and repetitive abortions. This is likely the case in our observation because the only probable risk noticed in the patient is the history of prior repetitive abortion. Other authors [7] [8] have similar cases.

The diagnosis of heterotopic pregnancy is difficult when the threatening conditions of miscarriage and miscarriage come in forefront. This often leads to misdiagnosis faced with the existence of IUP. That is the cause of the diagnostic delay and the management of EUP which is only noticed in a great number of cases at the stage of rupture with maternal and fetus lives threatening (IUP). The authors [9] agreed that it is necessary to think of ectopic pregnancy when deal- 
ing with IUP in the first trimester associated with latero-uterine mass with or without peritoneal signs. In our case, it is peritoneal sign that was predominant. Nevertheless, this diagnosis is easy with ultrasoundscan that highlights signs of complication of EUP (peritoneal fluid), of the two pregnancies or of the IUP associated with latero-uterine mass. The endoscopic surgery is the reference that permits to confirm the diagnosis and the treatment at the same time.

In our structure where this means of diagnosis is not available, we have used the information from the clinic features of chock (chock board) and the hemoperitoneum discovered at the emergency ultrasound to perform laparotomy. The endoscopic surgery is mainly practiced widely in well-equipped hospitals [10]. The medical treatment is possible by using methotrexate if IUP is not progressing, in contrast this product will be substituted to the potassium chloride for local injection. The fetal prognosticof IUG is better if the diagnosis is early and the morbid condition is absence. Thus, as it is the case in our observation, great number of live fetus (IUP) after treatment of EUP have been listed in the literature [10].

\section{Conclusion}

The diagnosis of heterotopic pregnancy must be always reflected on when dealing with a persistent pelvic pain at routine treatments despite the existence of intra-uterine pregnancy. The intra-uterine pregnancy would become more favorable with the increasing of early diagnosis and required treatment.

\section{Authorization of the Ethics Committee}

We, undersigned, authors of this article, give evidence to have received the authorization of the Ethics Committee of the Faculty of Medicine of Bamako.

\section{Conflicts of Interest}

The authors declare no conflicts of interest regarding the publication of this paper.

\section{References}

[1] Domenger, N.T. (1995) Heterotopic Pregnancies, Three Clinical Cases Report: Review of the Literature. Thesis of Medicine, Limoges, 45

[2] Traore, Y., Teguete, I., Mulbah, J.K., et al. (2006) Extra-Uterine and Intra-Uterine Pregnancy Association: 3 Cases Report. Mali Medical, 4, 35-38.

[3] Niang, M.M., Aidibe, I. and Cissé, C.T. (2013) Spontaneous Heterotopic Pregnancy at the Institute of Social Hygiene of Dakar: Three Cases Report and Review of Literature. Medicine of Black Africa, 60, 263-268.

[4] Rambel, A.H., Rakotovao, M. and Botolahy, Z.A. (2009) Heterotopic Pregnancy Revealed by a Rupture of Pregnancy: Clinical Fact. Revue Tropicale de Chirurgie, 3 , 59-60.

[5] Engongah-beka, T., Meye, J.F., Ozouaki, F., et al. (1997) Ruptured Intra-Uterine and Extra-Uterine Association: Two Cases of Different Evolution and Review of Li- 
terature. Medicine of Black Africa, 44, 8-9.

[6] Rabarikoto, H.F., Randriamahavonjy, R., Azrabetsimamanga, L., et al. (2010) Two Cases of Spontaneous Heterotopic Pregnancies at the Hopistal Center of Soavinandriana Antananarivo. Revue d Anesthésie-Réanimationet de Médecine d Urgence, 2, 21-24

[7] Achour, R., Ghades, S. and Naji, K. (2014) heterotopic Pregnancy: A Case Report and Review of Literature. Imagerie de la Femme, 24, 177-180. https://doi.org/10.1016/j.femme.2014.09.001

[8] Razafindraibe, A.F., Rafamantanantsoa, S., Rakotoarisoa, E., et al. (2015) Spontaneous Heterotopic Pregnancy with a Live Baby Delivered at 34 Weeks of Amenorrhea: A Case Report. Journal Malgache de Gynécologie-Obstétrique, 2, 10-11.

[9] Konan Blé, R., Adjoussou, S., Seni, K., et al. (2007) Ruptured Heterotopic Pregnancy with Delivery of a Live Baby at Term at CHU de Yopougon. Rev. Int. Sc. Méd., 9 83-87.

[10] Temine, R.B., Mathlouthi, N. and Makhlouf, T. (2012) Heterotopic Pregnancy: Seven Cases Report and the Review of Literature. Imagerie Femme, 22, 116-119. 